Journal of Information Systems Engineering

\& Management, 2018, 3(3), 21

ISSN: 2468-4376

\title{
Enterprise Architecture Proposal for Undergraduate Teaching in Higher Education Institutions
}

\author{
Sergio Araya-Guzmán 1*, Leyla Cares-Monsalves ${ }^{1}$, Patricio Ramírez-Correa 2, Elizabeth E. Grandón ${ }^{1}$, \\ Jorge Alfaro-Perez ${ }^{2}$
}

${ }^{1}$ Faculty of Business Sciences, University of Bio-Bio, Concepción, CHILE

${ }^{2}$ Engineering School, Catholic University of the North, Coquimbo, CHILE

\section{*Corresponding Author: saraya@ubiobio.cl}

Citation: Araya-Guzmán, S., Cares-Monsalves, L., Ramírez-Correa, P., Grandón, E. E. and Alfaro-Perez, J. (2018). Enterprise Architecture Proposal for Undergraduate Teaching in Higher Education Institutions. Journal of Information Systems Engineering \& Management, 3(3), 21. https:/ / doi.org/10.20897/jisem/2657

Published: July 16, 2018

\begin{abstract}
This work, which is part of an ongoing project, presents the first steps of a proposal Enterprise Architecture (EA) for the area of Undergraduate Teaching in Higher Education Institutions. The University of Bío-Bío (Chile) is considered as a case of initial study, with the purpose of identifying strategic guidelines, processes, systems and information technologies, which will serve as a basis to define a model of AE, which will be validated in other institutions, in order to identify common patterns that allow building a general model of utility to support the development, management and operation of this area, and also collaborate, promote and facilitate the achievement of institutional goals.
\end{abstract}

Keywords: enterprise architecture, university higher education institutions

\section{INTRODUCTION}

Organizations have been permanently concerned about improving their performance (Araya and Chaparro, 2005), (Porter, 1980), (Robinson and Pearce II, 1998), (Rojas, Sánchez and Guerrero, 2015), (Scott, 2015). The achievement of better performance and competitive advantages may be associated with the alignment between Information Systems and Technologies Systems (IS/TS) and the organization's strategy (Kearns and Lederer, 2000), (Tian et al., 2010). In this business strategy - IS/TS strategy relationship, the Enterprise Architecture (EA) emerges as a holistic connection between business processes, information systems and information technology infrastructure (Lankhorst, 2005.)

This study, which is the first advance of an ongoing project whose objective is to propose an EA for the area of Undergraduate Teaching of University Higher Education Institutions in Chile, considering guidelines for quality assurance, presents the first advances after carrying out the initial phases established for the achievement of this objective. To this end, the University of Bío-Bío (Chile) has been considered as a case study base to obtain an initial vision of a possible enterprise architecture, which later, under the corresponding analyses and considerations, can be generalized to more institutions.

The general stages considered for the development of this research are: (i) a review of the literature on EA, (ii) the development of phases associated with the definition of an EA for undergraduate teaching, (iii) the validation of the EA proposal against a sample of these Institutions, (iv) the development of necessary adjustments, (v) the presentation of a definitive proposal. In this paper, the progress made up to the second stage is presented. 


\section{REVIEW OF THE LITERATURE AND PROBLEM STATEMENT}

Improving organizational performance has been a permanent concern for organizations (Porter, 1980; Ramanujan et al., 1986; Robinson and Pearce II, 1998; Tian et al., 2010; Turban et al., 2015), where the achievement of better performance levels and competitive advantages may be motivated by the existing alignment between IS/TS and the organization's business strategy (Kearns and Lederer, 2000; Gupta et al., 1997; Chan and Reich, 2007; Gragg et al., 2002; Tian et al., 2010). In this sense, through a continuous process of aligning Information Technology (IT) and business strategies, organizations can develop these competitive advantages and improve their performance (Chan and Reich, 2007; Kearns and Lederer, 2000; Croteau and Bergeron, 2001; Bergeron et al., 2001; Rocha and Freixo, 2014; Rocha and Sá, 2015; Turban et al., 2015).

In this business strategy - IS/TS strategy relationship, there is a holistic, integrating alignment that contemplates business processes, information systems and technological infrastructure, called EA (Zachman, 1987). According to Lankhorst (2005), enterprise architecture "is a coherent set of principles, methods and models that are used in the design and implementation at the enterprise level of organizational structure, business processes, information systems and infrastructure", where all elements of information technology, processes, systems, organizational structure and people are integrated and work together as a whole (Lankhorst, 2005).

According to Bernard (2015), any organization can be structured according to three hierarchical levels: strategy, processes, and information systems. At the first level, the organization establishes the objectives it intends to achieve; at the process level, the necessary operations to achieve the objectives defined in the strategy are established, while at the third level, the aim is to provide the necessary support to systems for the development of the processes and the scope of the strategic purposes established, with the support of the appropriate information technology infrastructure (platforms, operating systems, databases, networks and telecommunications.)

A particular type of organization, which is also faced with a constant search for excellence, corresponds to Institutions of University Higher Education (Araya and Chaparro, 2005). These organizations have also been concerned about improving their performance levels, due, for example, to the overcrowding of higher education systems and limitations in public spending (Araya et al., 2007), and must incorporate and adapt to technological changes, where the use of information systems is relevant to improving their performance and competitiveness, in an increasingly demanding educational environment (Araya and Chaparro, 2005). These requirements have become a challenge for these types of institutions, where there has been a growing interest in improving the efficiency in the use and management of their human, financial, material, technological and information resources.

Higher Education Institutions, like any other organization, must have strategic guidelines that specify where they want to go and the path to follow to achieve it, where objectives and goals are established, as well as strategies for their fulfillment, defining and implementing processes, procedures, mechanisms, activities, tools, resources and capacities necessary to achieve the purposes pursued.

In Chile, Higher Education Institutions face a constant search for excellence (Ramírez-Correa et al., 2012), where a culture of quality has been developed, within the framework of continuous improvement, strongly promoted by the processes of institutional accreditation and accreditation of undergraduate and graduate programs. In this sense, the accreditation processes, at any level, require a look at a series of institutional aspects, considering elements related to teaching, management, research, outreach, technical assistance, planning, liaison to employers, follow-up and linkage with graduates, dissemination, student services, among others, which undoubtedly includes the set of institutional resources involved, whether human resources, infrastructure, equipment, facilities, financing, etc.

Studies, such as that of Rojas, Sánchez and Guerrero (Rojas, Sánchez and Guerrero, 2015), present the design of an Enterprise Architecture Model for the macro process of Academic Management of the University of Pamplona, pointing out that this model "provides a new way of seeing the macro process mentioned, where the control of the process can be improved, as well as its evolution and changes"

In this context, the definition and implementation of an Enterprise Architecture for Higher Education Institutions can be a convenient strategy that promotes the alignment between the purposes, processes and information systems that intervene in the work of these institutions. Moreover, if this alignment exercise includes aspects that are considered in the quality assessment (accreditation) within these organizations, it allows for the incorporation of elements that should be considered and that these institutions should take into account in order to improve their performance and quality levels (Araya et al., 2018.)

\section{METHODOLOGY}

The stages considered for the development of this research are: (i) a review of the literature on EA, (ii) the development of phases associated with the definition of an EA for undergraduate teaching, (iii) the validation of 
Table 1. Strategic guidelines, processes

LE1 Undergraduate Teaching Educating Integral Persons of Excellence for the development of Society

Strengthen the systems of measurement, monitoring and control of the phases that comprise the process of harmonization of

OE1.1 undergraduate programs with the institutional educational model, updating and tuning the corresponding standards and regulations.

OE1.2 Strengthen the process of permanent self-evaluation to achieve and maintain accreditation of all undergraduate and graduate programs that can be accredited.

OE1.3 Establish policies and manage resources to improve the infrastructure and equipment for the development of academic, teaching

OE1.3 and extra-curricular activities of students at the Universidad del Biobío

To strengthen the processes of vertical articulation, with the secondary education, both scientific - humanistic and technical

OE1.4 professional, the programs of insertion and adaptation to the university life with the purpose of improving the admission and positioning the academic offer of the Universidad del Biobío.

OE1.5 To strengthen the capacities and teaching skills of the academic staff of the Universidad del Biobío, to improve classroom

OE1.5 performance and encourage the development of research in teaching.

P1 Formulate and update Educational Model

P2 Design Careers according to Educational Model

P3 To strengthen teachers according to the Educational Model

P4 Teaching according to the Educational Model

P5 Self-assessment of Careers

P6 Accredit Careers

P7 Execute Improvement Plan

P8 Manage academic, teaching, and extracurricular activities of students

P9 Manage Student Projects according to Educational Model

P10 Manage infrastructure and equipment

P11 Manage activities of vertical articulation

P12 Assess results vertical articulation

P13 To insert and adapt new students

P14 Manage tutoring programs

P15 Manage teacher support trainings

P16 Manage teaching results by teacher

P17 Manage Research in teaching

S1 Manage Educational Model

S2 Manage Undergraduate Programs

S3 Manage Design / Adjustment / Redesign Curriculum

S4 Manage Generic UBB Student Profile

S5 Manage Graduate Profile

S6 Manage Teacher Training and Development

S7 Manage Commitments by Faculty-Department-School-Faculty-Teacher

S8 Manage Teaching Resources

S9 Manage Teaching Session

S10 Manage career self-assessment-accreditation processes

S11 Manage follow-up of Improvement Plans

S12 Manage teaching, student and extracurricular activities of students

S13 Manage projects according to Educational Model

S14 Manage infrastructure and equipment

S15 Manage vertical articulation activities

S16 Follow-up of new students benefiting from Vertical Art.

S17 Inserting and adapting new students

S18 Manage tutorial and people receiving tutorials

S19 Manage Teacher's Training Plan regarding Teaching

S20 Manage results by teaching

S21 Manage teaching research

the EA proposal against a sample of these Institutions, (iv) the development of necessary adjustments, (v) the presentation of a definitive proposal. In this paper, the progress made up to the second stage is presented.

The phases of development associated with the EA for Undergraduate Teaching are the following:

1. Phase 1: Identification of defined strategic aspects.

2. Phase 2: Identification of processes associated with the development of strategic aspects (Business Architecture.)

3. Phase 3: Identification of information required for the execution of the established processes (Information Architecture.)

4. Phase 4: Identification of computer applications required to support the processing of information and the execution of the processes involved (Information Systems Architecture.)

5. Phase 5: Identification of the necessary information technology infrastructure (platforms, operating systems, databases, networks and telecommunications) (Technological Architecture) for the development and support of the computer applications established. 


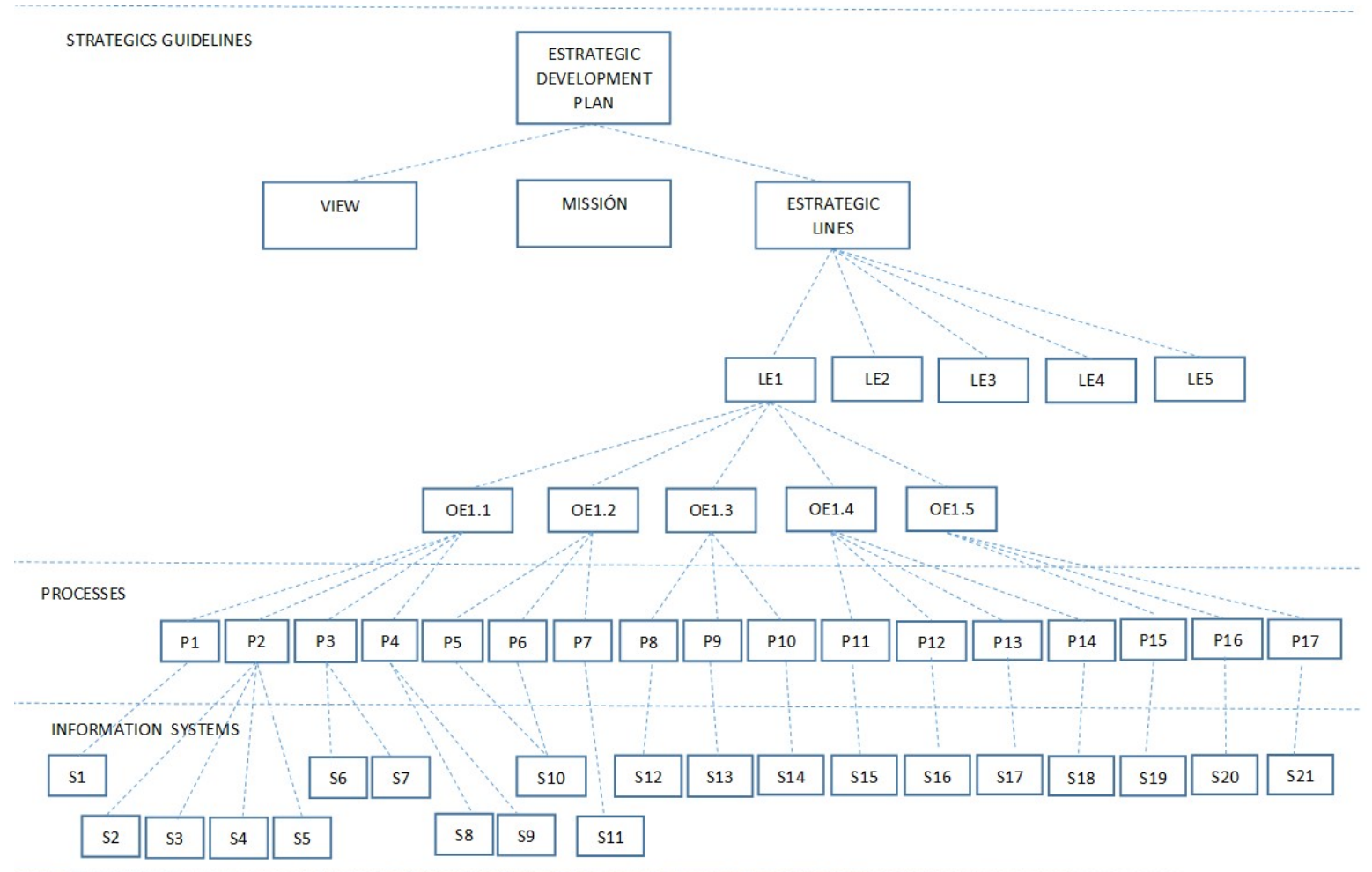

Figure 1. Graphical representation of strategic guidelines, processes and information systems, and their relationship to each other

\section{RESULTS}

The University of Bío-Bío has defined a strategic development plan which establishes that within its Mission is, among other elements, the quality Undergraduate Teaching, which includes the various aspects directly related to the training process. In its strategic development plan, it has defined five strategic lines, the first of which is directly related to Undergraduate Teaching, specifically: (LE1) "Undergraduate Teaching Educating Integral Persons of Excellence for the development of Society". This strategic line contemplates five strategic objectives that consider, in general, aspects or approaches similar to those of other universities, specifically: (EO1.1) design, adjustments and curricular redesign aligned with the educational model, under current regulations, (EO1.2) selfevaluation of undergraduate programs on a permanent basis to strengthen their quality levels, (EO1.3) infrastructure and equipment for the development of academic, teaching and extracurricular activities of students, (EO1.4) vertical articulation with secondary schools, and insertion and adaptation of new students to university life, (EO1.5) training of teachers to improve their performance in the classroom and the development of research in teaching.

Although Undergraduate Teaching is directly related to Strategic Line 1, it can also be related to the other strategic lines associated with Management, Research, Postgraduate Teaching, Linking with the Environment, etc.

Based on the strategic objectives stated, a first identification has been done of: processes associated with those objectives, information and computer applications required in such processes, which can be enriched in a subsequent revision and in the validation process with different institutions. It is also necessary to determine the information technologies required. Table 1 presents the strategic guidelines, the processes identified, and the information systems required, which are shown graphically in Figure 1, where the relationship among them can be seen.

\section{WORK TO BE DONE}

The final model of the Enterprise Architecture for Undergraduate Teaching must be validated by different institutions, whose feedback will collaborate with the development of the necessary modifications and/or adjustments to establish a general model for these organizations under common standards.

In addition, the criteria for institutional accreditation of the Undergraduate Teaching area applied in Chile by the National Accreditation Commission will be considered, in order to ensure that all these criteria are covered 
with the required information, necessary processes, defined strategic guidelines, and possible computer applications, or if necessary, modifications, adjustments or incorporating new aspects that ensure the coverage of the criteria mentioned above, which will contribute favorably to future accreditation processes.

\section{CONCLUSIONS}

University higher education institutions use a variety of information systems and technologies for the development of their activities, which when integrated with the strategic guidelines can produce better benefits. In this sense, EA is a powerful organizational tool for improving performance levels.

Since the area of Undergraduate Teaching is a key area in these institutions, it can be crucial to have an EA that provides support and back-up for their development, management and operation, collaborating, promoting and facilitating the achievement of the goals and objectives defined.

Undoubtedly, an EA for all the areas developed by these institutions would have a greater effect, which would constitute an expansion of this proposal and a great progress in the integration of the strategic guidelines and information systems of these organizations.

\section{REFERENCES}

Araya, S., Cares, L., Grandón, E., Ramírez, P., and Alfaro, J. (2018). Explorando una Arquitectura Empresarial para Instituciones de Educación Superior Universitaria: Una propuesta para el Área de Docencia de Pregrado (Exploring an Enterprise Architecture for University Higher Education Institutions: A proposal for the Undergraduate Teaching Area). In Information Systems and Technologies (CISTI), 2018 13th Iberian Conference on (pp. 1-5). IEEE.

Araya, S. and Chaparro, J. (2005). Una aplicación del Análisis de Recursos y Capacidades en el ámbito de Instituciones de Educación Superior Universitaria (An application of the Analysis of Resources and Capacities in the field of University Higher Education Institutions). Congreso de Ingeniería de Organización (CIO). Available at: http:/ / www.adingor.es/Documentacion/CIO/cio2005/items/ponencias/110.pdf

Araya, S., Chaparro, J., Orero, A. and Joglar, H. (2007). Sistemas y Tecnologías de Información y su relación con el Desempeño de Instituciones Universitarias en el ámbito de Gestión Institucional: un estudio desde la Teoría de Recursos y Capacidades (Information Systems and Technologies and their relationship with the Performance of University Institutions in the field of Institutional Management: a study from the Theory of Resources and Capacities). In International Conference on Industrial Engineering \& Industrial Management (pp. 1805-1816). Congreso de Ingeniería de Organización Available (CIO). at: http:/ / www.adingor.es/congresos/web/uploads/cio/cio2007/information_systems_ict//1805_1816.pdf

Bergeron, F., Raymond, L. and Rivard, S. (2001). Fit in strategic information technology management research: an empirical comparison of perspectives. Omega, 29,125-142. https://doi.org/10.1016/S0305-0483(00)00034-7

Bernard, S. (2015). An introduction to enterprise architecture, author House, Third Edition, Indiana, EEUU.

Chan, Y. E. and Reich, B. H. (2007). IT alignment: what have we learned? Journal of Information Technology, 22(4), 297-315. https://doi.org/10.1057/palgrave.jit.2000109

Cragg, P., King, M. and Hussin, H. (2002). IT alignment and firm performance in small manufacturing firms, Journal of Strategic Information Systems, 11, 109-132. https:/ / doi.org/10.1016/S0963-8687(02)00007-0

Croteau, A. and Bergeron, F. (2001). An Information Technology Trilogy, Business Strategy, Technological Deployment and Organizational Performance, Journal of Strategic Information Systems, 10(2), 77-99. https://doi.org/10.1016/S0963-8687(01)00044-0

Gupta, Y. P., Karimi, J. and Somers, T. M. (1997). Alignment of a firm's competitive strategy and information technology management sophistication: the missing link, IEEE Transactions on Engineering Management, 44(4), 399-413. https://doi.org/10.1109/17.649870

Kearns, G. and Lederer, A. (2000). The effect of strategic alignment on the use of IS-based resources for competitive advantage. The Journal of Strategic Information Systems, 9(4), 265-293. https:/ / doi.org/10.1016/S0963$8687(00) 00049-4$

Lankhorst, M. (2005). Enterprise architecture at work: modelling, communication, and analysis. Berlin: Springer-Verlag.

Porter, M. (1980). Competitive Strategy: Techniques for Analyzing Industries and Competitors, New York: Free Press.

Ramanujan, V., Venkatraman, N. and Camillus, J. (1986). Multi-objective assessment of effectiveness of strategic planning: a discriminant analysis approach. The Academy of Management Journal, 29(2), 347-372.

Ramírez-Correa, P., Peña-Vinces, J. C. and Alfaro-Pérez, J. (2012). Evaluating the efficiency of the higher education system in emerging economies: Empirical evidences from Chilean universities. African Journal of Business Management, 6(4), 1441-1448. https://doi.org/10.5897/AJBM11.1982 
Robinson, R. and Pearce II, J. (1998). Planned patterns of strategic behavior and their relationship to business-unit performance. Strategic Management Journal, 9(1), 43-60. https:// doi.org/10.1002/smj.4250090105

Rocha, Á. and Freixo, J. (2015). Information architecture for quality management support in hospitals. Journal of Medical Systems, 39(10), 125. https:/ / doi.org/10.1007/s10916-015-0326-z

Rocha, A. and Sá, F. (2014). Planning the information architecture in a local public administration organization. Information Development, 30(3), 223-234. https://doi.org/10.1177/0266666913489841

Rojas, W., Sánchez, M. and Guerrero, W. (2015). Diseño de un modelo de Arquitectura Empresarial para el macro proceso de gestión académica de la Universidad de Pamplona. ("Design of an Enterprise Architecture model for the macro academic management process of the University of Pamplona"), Revista Colombiana de Tecnologias de Avanzada, 2(26), 80-85.

Scott, A. B. (2015). An introduction to enterprise architecture, author House, Third Edition, Indiana, EEUU.

Tian, J., Wang, K., Cheng, Y. and Johansson, B. (2010). From IT deployment capabilities to competitive advantage: An exploratory study in China, Information Systems Frontiers, 12(3), 239-255. https://doi.org/10.1007/s10796009-9182-z

Turban, E., Volonino, L. and Wood, G. (2015). Information Technology for Management: Digital Strategies for Insight, Action, and Sustainable Performance, Hoboken: John Wiley \& Sons.

Zachman, J. A. (1987). A Framework for Information Systems Architecture. IBM Systems Journal, 26(3), 454-470. https://doi.org/10.1147/sj.263.0276 